\title{
Retinal Hemangioblastoma
}

National Cancer Institute

\section{Source}

National Cancer Institute. Retinal Hemangioblastoma. NCI Thesaurus. Code C39783.

A hemangioblastoma that arises from the retina. It is typically a sign of von Hippel-Lindau disease. It may also be seen as an isolated entity without systemic involvement. 